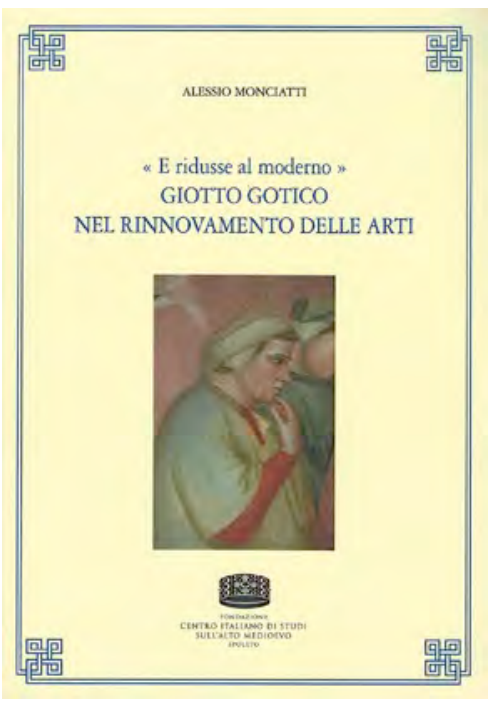

Alessio Monciatti

Giotto i I'impuls modernitzador del gòtic

"E ridusse al moderno". Giotto gotico nel rinnovamento delle Arti

Fondazione Centro Italiano di Studi Sull'alto Medioevo, Spoleto, 2018

\section{Giotto i I'impuls modernitzador del gòtic}

El número 57 de la col·lecció Uomini e Mondi Medievali de la Fundació del Centro Italiano di Studi sul Basso Medioevo de Spoleto i el Centro Italiano di Studi sul Basso Medioevo de Todi ens sorprèn amb un títol dedicat a Giotto que no hauria de passar-nos desapercebut. L'autor, Alessio Monciatti, és catedràtic del departament de Scienze Umanistiche Sociale e della Formazione de la
Universitat del Molise i ha col.laborat freqüentment amb el nostre grup de recerca, integrat en alguns dels nostres projectes. EI seu recorregut docent i els importants estudis sobre l'art medieval italià que ha publicat, entre els quals hi ha els consagrats al Palau dels papes de Viterbo o a les arts italianes del Duecento, avalen una carrera brillant. Ara concatena amb I'afany de resseguir el món del segle XIII un nou assaig, aparegut I'octubre del 2018, que palesa el seu interès pel segle XIV, ja ben manifest en treballs precedents. EI Trecento emmarca així la seva monografia sobre una de les grans etapes creatives de Giotto di Bondone.

Centrat en I'anàlisi d'un període que va ser cabdal per al desenvolupament de l'obra del cap d'escola florentí, el llibre configura un context d'exploració espaiós en què pesen els treballs del taller, dels collaboradors i dels seguidors. Es recupera aquí una atmosfera empesa per un afany de renovació general. L'etapa analitzada revisa la creació de Giotto després de la fase que descriu immiIlorablement la capella de I'Arena de Pàdua, obra de fama universal, visitada reiteradament tant per la crítica especialitzada com pels divulgadors, i s'atura abans del periple del pintor pel regne de Nàpols, un tema, aquest darrer, abordat en I'enorme estudi per Ferdinando Bologna i, més recentment, per Pierluigi Leone di Castris i altres autors. El professor Monciatti es proposa endinsar-nos en un dels espais creatius del mestre que ha estat menys explorat per la crítica i que, malgrat això, és tan dens com significatiu. No debades, pressuposa I'estudi de les decoracions de les capelles Bardi i Peruzzi de la Santa Croce de Florència, dels cicles murals de la basílica inferior d'Assís, al transsepte dret i a les voltes del creuer, i d'encàrrecs florentins i de la Cúria que van acréixer l'activitat del taller en aquest període central.

En primer lloc, vull celebrar I'encert d'un títol que convida a veure en Giotto, no I'artista que inicia quelcom sense arribar a coronar el cim, sinó un fruit perfecte de la seva època, capaç de condicionar-la i renovar-la. Sense deixar $d^{\prime}$ obrir expectatives al futur pictòric europeu, el creador és independent de I'esdevenidor, que li resulta aliè. De fet, el canvi ja es troba a les seves mans $i$ ha de brillar a la llum que li pertany. Podem afirmar que el toscà es converteix en la nova columna del Gòtic avançat que posa fonaments per a noves experiències sense haver de convertir-se en un mer afluent vers el gran riu del Renaixement. Potser des d'Itàlia, sempre submergida en la contemplació de I'antic, el terme gòtic s'ha associat inevitablement a les derivades franceses i septentrionals que dominaren el corrent des dels segles XII i XIII enllà, però, analitzades les coses des de Catalunya, la concepció del Gòtic sempre és més oberta i no pot entendre's sense apreciar l'art singular dels centres italians. Són segles tan nuats al món medieval com inspiradors d'una transformació punyent. S'hi 
manifesten, sota l'etiqueta que sigui, alternatives vàlides i innovadores amb la base antiga indefugible i una cultura autòctona única que, sense negar-lo del tot, ofereix espectaculars alternatives a l'art gòtic del nord dels Pirineus i torna a incidir més tard també en aquesta geografia. Per tant, és necessari entendre el Gòtic com quelcom que no pertany a una geografia europea precisa i del qual no poden quedar fora els grans centres meridionals que més i millor enriqueixen el període. Els segles XIII i XIV s'inscriuen en aquesta etapa, tan convencional $\mathrm{i}$ trencadissa en els seus episodis concrets com ho pot ser la del Renaixement o la del Barroc, si no volem parar esment en altres interessants capítols anteriors 0 posteriors. En fi, un «Giotto gòtic» pertany al meu imaginari més que no pas un Giotto prerenaixentista o protorenaixentista. Aquest llibre arriba per afermar aquesta idea, encara que l'autor es curi en salut i adverteixi que l'adjectiu gòtic pot semblar "difficoltoso» aplicat a Giotto. S'ha de capturar la indicació i, en tot cas, aplaudir el Giotto gotico del títol, lluny de les panoràmiques tendents a fer desaparèixer una esplèndida Edat Mitjana que, sigui més o menys bizantina, romànica o gòtica, ens apropa al focus de I'art italià.

Aquestes consideracions no tenen I'objectiu de negar I'especificitat dels centres italians, tot al contrari, la idea és valorar-ne l'alt relleu específic dins l'Europa que transforma, pas a pas i sense trencaments de la nit al dia, l'art i la tradició que introduirà el Renaixe- ment. Una etapa que, és ben clar, no ha d'escapar del tot als registres més pesants i autoritzats del Gòtic. Aquest plantejament de fons posarà I'èmfasi en algunes paraules de Cennino Cennini quan afirma que Giotto «rimutò I'arte del dipingere di greco in latino e ridusse al moderno, ed ebbe l'arte più compiuta che avesse mai più nessuno».

Traduir la paraula italiana ridusse, aplicada a «ridusse al moderno», té la seva complicació, perquè I'opció literal 'reduït al modern' no equivaldria pròpiament a la idea expressada en italià. Potser 'transportar', 'concentrar', 'amarrar' o 'subjectar' al modern, s'acostarien al concepte metafòric que explota la fórmula aplicada en Ilengua italiana. Sigui com sigui, no s'ha d'entendre com a minva de res, sinó com a sistema $d^{\prime}$ 'integració en un ordre transfigurat que obre camins a les novetats que arriben per quedar-se, és a dir, remeten a una mudança que engendra I'al.ludida modernitat; un altre concepte, modernitat, tan influent com creador de subtils «jeroglífics».

El primer capítol de Monciatti s'endinsa en la problemàtica específica de la capella Peruzzi. Dedicada als sants Joans, és esmentada per primera vegada en la documentació dels anys 1335 i 1336, quan ja es planteja la necessitat d'algunes reparacions i adobaments. Les fonts són avares i deixen l'encàrrec en la penombra, però l'autor fa una revisió detallada de totes les dades disponibles i posa sobre la taula les qüestions més pertinents. El sojorn del rei Robert de Nàpols a la casa dels Peruzzi dal Parlagio, a Florèn- cia, els mesos de setembre i octubre del 1310, quan tornava d'Avinyó, on havia estat coronat, dona gruix al tema dels promotors i els encàrrecs a Giotto. La idea d'una capella familiar s'imposa, a parer de I'autor, que recolza la consideració en fonts diverses, entre les quals hi ha la Vita di Giotto de Vasari. Els rostres dels Peruzzi, imaginats com a collectiu familiar, es farien visibles a la capella a manera de sintètics retrats 0 , en qualsevol cas, $d^{\prime}$ imatges al-lusives al patrocini $d^{\prime}$ un clan de comitents que es representen en funció de la seva edat i el seu estatus, més que no pas a partir de fisonomies específiques. No cal dir que la dedicació de la capella als sants Joans escau al context franciscà, tal com corroboren altres programes de l'orde. Tot seguit, l'autor fa la interpretació acurada del programa, de les pèrdues i dels trets més notoris, fent al mateix temps les oportunes comparacions. Les solucions hagiogràfiques difonen un embolcall temàtic de caire visionari i apocalíptic que, associat al context funerari i franciscà, explica el cicle i la intenció, o cúmul d'intencions, que s'hi expressen. La determinació cristològica pròpia dels franciscans arriba adaptada a les necessitats dels Peruzzi, insignes patrons burgesos, i a la visió d'una salvació que tots esperen obtenir.

No puc entrar en la valoració de les obres perdudes o desplaçades, també apreciades en el llibre, en què s'al.ludirà al problema de I'altar de la capella, vestit amb una «Tavola Peruzzi» que es proposa acostar al políptic Raleigh. Des 
d'una altra perspectiva, cal atendre les consideracions sobre l'estat precari de conservació d'uns murals insignes, alhora que es colloca l'accent sobre la tècnica del pintor $\mathrm{i}$ I'ús refinat que fa de la pintura a secco. El trencament amb la duresa plàstica de l'estil de joventut és un dels punts d'inflexió que bé calia posar en relleu, així com la summament important relació de Giotto amb el món de l'arquitectura i I'escultura. Emergiran noms com els d'Arnolfo di Cambio o Giovanni Pisano, més enllà de les anàlisis sobre el vincle, també oportú, amb I'escultura francesa del segle XIII. Valorades les connexions amb altres obres del mestre florentí, que obliguen a fer passos vers els murals d’Assís i Pàdua, Monciatti situa els murals de la capella Peruzzi a I'entorn del 1310, avaluant les dades documentals disponibles, i conclou que I'obra es devia realitzar en el marc d'un taller plural pocs anys després de finalitzar la intervenció a la capella de I'Arena de Pàdua, on devia pintar a I'entorn del 1305.

En el darrer apartat d'aquest primer capítol, les pintures de la Santa Croce són definides com a dilema (o crocevia) per a la pintura florentina: un vèrtex d'estil. S'hi aprecia el compromès paper de I'anomenat Parente di Giotto i la seva incidència en el nucli pictòric toscà que no refusa l'entourage imponent del cap d'escola. Entre d'altres, ressonaran els noms, d'abast desigual, del Maestro della Santa Cecilia (apropat a Gaddo Gaddi), el Maestro di Mezzana, Pacino di Bonaguida, el Maestro del Trittico Horne, Jacopo del Casentino, el
Maestro delle Velle, el Maestro Espressionista di Santa Chiara (apropat a Palmerino di Guido), Buonamico Buffalmacco, Stefano, el Maestro di San Nicola, Giuliano da Rimini, el Maestro di Figline, Rico di Lapo (gendre de Giotto), o Puccio Capanna.

Sobre aquestes bases, posades en una seixantena llarga de pàgines, s'aixequen els capítols restants del llibre, que no puc ressenyar amb el detall amb què ho he fet amb el primer. El lector interessat hauria de llegir-los amb atenció i, això sí que puc avançar-I'hi, tots el captivaran per la seva magnitud $\mathrm{i}$ precisió. Entrar en el debat sobre les obres resulta molt atractiu, ja que, com és força obvi, no tots els interrogants oberts sobre aquestes produccions i llurs creadors tenen fàcil solució o porten al consens després de la interpretació de les dades i els materials disponibles. Monciatti tracta amb elegància les diverses vies d'estudi obertes per uns $i$ altres i ens permet penetrar en els problemes. Per tant, ens ajuda a formar criteri, estiguem d'acord o no amb el seu punt de vista o amb totes les seves conclusions. L'evolució de I'estil de Giotto sobrevola els escenaris toscans i umbres amb què ens confrontem, com un aspecte fonamental per a la seva interpretació que, tanmateix, no pot menystenir les correspondències amb un taller compost en el qual s'ha assumit i es predica la matriu del mestre principal. No dubtem que, com assenyalava Vasari i ens recorda Alessio Monciatti en el seu llibre, Giotto «fu studiosissimo et andò sempre nuove cose pensando e dalla natura cavando». Ho haurem de redescobrir a partir de les qüestions concretes $\mathrm{i}$ teòriques que fan del plural un singular i del singular un plural dins d'un taller (la bottega) en què la figura mítica de Giotto actua com a genial director d'orquestra, o director operum, un càrrec que cal sospesar dins dels marges possibles que ofereix el treball d'equip. Amb taller estable a Florència, Giotto hauria estat pendent d'altres projectes que el convocaven, en l'etapa analitzada, fonamentalment a la franciscana Assís (capítol II). La pintura sobre taula havia de robar temps al temps que en demanaven els grans cicles murals en obra, a la ciutat natal o en altres centres. Entre aquestes taules sobresortiran la coneguda Madonna di Ognissanti, estretament vinculada per tempo estilístic als murals de la capella Scrovegni, i la deliciosa Dormitio Virginis, de la Gemäldegalerie de Berlín, de la mateixa procedència, que, pintada amb subtilesa i força, es distancia de la primera perquè conjuga uns equilibris compositius més suaus o menys tensos i un refinament plàstic que crida l'atenció a primer cop d'ull (capítol ini). Segons apuntarà Giorgio Vasari, el Trànsit de Maria — fonamentat sobre els antics models de la Kóimesis bizantina - era situat en el tramezzo de l'església, desaparegut entre 1564 i 1566. Monciatti se n'ocupa alhora que ho fa de la monumental Creu pintada d'Ognissanti, que, emplaçada per la crítica entre les mans del Parente de Giotto i Giotto mateix, se situa entre 1311 i 1315. L'assaig fa un recor- 
regut per taules que ens guien fins a París, Berlín, Munic, Troyes, Estrasburg, Londres, Florència i Roma, sense deixar-se algunes peces conservades a Amèrica, ja sigui a Nova York, a Washington o a Boston. És interessant revisitar els fragments de la badia de Florència, que donaria a conèixer Procacci i que porten a pensar en I'enfocament de la capella Bardi i en la grandesa d'aquestes primeres pintures, que observem avui dia esmicolades de forma lamentable.

Segueixen els capítols dedicats a valorar el pas de Giotto per Roma (capítol IV), molt succintament documentat. Tanmateix, Roma és Roma i Giotto és Giotto, i una combinatòria tal permetrà a l'autor, sempre amb cura i amb una valuosa ponderació historiogràfica, abordar temes centrals com el de la Navicella degli apostoli o el políptic Stefaneschi. El mosaic, consagrat a revelar la situació difícil del papat, amb una monumental nau de l'església, fou un encàrrec primerenc de Jacopo Stefaneschi. Destinat a I'atri de Sant Pere del Vaticà, es convertiria en una de les més lloades creacions del florentí. El políptic, en canvi, té un abast diferent $\mathrm{i}$ acull dues vegades la figura del donant. Reclama una cronologia més avançada i la contribució d'alguns colllaboradors del taller. S'especifica que I'obra es devia destinar a I'altar principal de la basílica de Sant Pere «super eiusdem basilice sacrosanctum altare». Em sembla molt assenyada la proposta de convenir sobre la datació del políptic que ofereix el notari pontifici Gri- malni el 1603, el qual el reconeixia «manu Jotti pictoris eximij circa annum D(omi)ni Mcccxx depi(n) cta». Es remarquen, doncs, les raons per les quals una datació entorn del 1320 és veritablement oportuna. Els arguments em semblen convincents i especialment interessants per a l'anàlisi d'alguns dels desenvolupaments de la pintura catalana del segon quart del segle XIV.

Un altre capítol important per a la valoració de la nostra pintura passa per Avinyó, centre indispensable per aprofundir l'anàlisi de I'obra dels Bassa i de llur temps. En aquesta disjuntiva s'emplaça el relliscós tema de Giotto i Avinyó, una vessant que no es defuig a I'assaig de Monciatti i que compondria la teoria sobre els efectes d'un viatge del pintor de Florència més enllà dels Alps, cosa que, sense haver estat provada, no hauria estat impossible, a parer de l'autor.

Amb aquesta ja complexa definició arribem al capítol v, que es consagra complet a la capella Bardi de la Santa Croce, la qual, dedicada al fundador de l'orde franciscà, va ser pintada en allò fonamental per Giotto, com és reconegut universalment. Allargaríem molt aquesta ressenya si entréssim en els detalls de l'exposició d'Alessio Monciatti. Pas a pas, el capítol ens introduirà en les informacions que avalen el patronatge, relacionat amb Ridolfo de Bardi, la construcció de la capella i el programa que s'hi va definir. Un tema que cal destacar, en tot cas, és el que fa allusió a un primer substrat pictòric de caire geomètric o decoratiu que precediria I'encàrrec a Giotto. Una altra qüestió seria la intervenció del Maestro di Figline i el pes dels vitralls en el conjunt sacre, i encara una altra, la més Ilarga, la valoració detallada del cicle franciscà complet. Es percep com la vida del sant es projecta enfora i transcendeix els murs de la capella mateixa: "La collocazione all'esterno della scena cruciale di Francesco riceve le stimmate coinvolge complessivamente il capocroce nell'esaltazione del parallelismo Francesco/Cristo, decisivo per intendere nella imitatio Christi la chiave di lettura della dispositio complessiva, declinata nei termini della compassio e della conformitas, vissute e acquisite proprio attraverso le stimmate» (p. 217). A partir d'aquí ens podem introduir en passatges diversos de la vida de sant Francesc per mirar d'entendre I'objectiu del programador i prosseguir amb les comparacions pertinents, sobretot amb les que de nou menen a Assís i que colpirien, ara i adés, en un escenari d'una complexitat immensa. La definició formal i tècnica dels murals ens anirà revelant els nexes amb altres creacions, que es defensen amb arguments sempre rigorosos, a la vegada que situen les novetats aportades per I'obra de Giotto en un context de reconeguda competència. S'estudia el paper dels collaboradors, tot i que es vindica la notabilíssima coherència del cicle, uns fets que no han de ser descrits com a contradictoris. No puc deixar la capella Bardi sense al-ludir al nexe que mena a Nàpols a través dels murals analitzats en aquest 
assaig, un aspecte que estimo capital també per a l'anàlisi de la nostra pintura i que Monciatti introdueix per tal de retornar sobre el context creatiu que abraça Giotto, conjuntament amb altres pintors $d^{\prime}$ indiscutible qualitat, entre els quals hi ha Maso di Banco i Taddeo Gaddi. Al capdavall, la cronologia mateixa que es pot atribuir al conjunt de la Santa Croce confirma la connexió amb el viatge al regne del rei Robert, ja que ens apropa als anys vint del segle XIV, en el període immediatament anterior a I'anada i sojorn de Giotto a la Campània (1328-1333). En el cas de la capella Bardi, però, Monciatti apunta el 1320, moment que coincidiria poc o molt amb la datació volguda per al políptic Stefaneschi. És una proposta que caldrà meditar i que, seguida estrictament, en el fons, ens tornaria a allunyar una mica dels anys napolitans.

Finalment, el treball realitzat ens revela encara l'interès de l'autor pels fets historiogràfics i se submergeix en una visió que fa cabal del llarg recorregut que consolida la fama i la centralitat del problema tractat (capítol VI). El pas per la Santa Croce florentina dels Burckhardt, Taine o Ruskin, entre altres estudiosos, arriba per revisar opinions diverses sobre el monument i les pintures, no privades de vegades d'un deix d'heretgia $i$ encarades a bastir un discurs que tindrà seguiment com a forma de reconeixement indiscutible de la tasca realitzada per Giotto. No hi ha dubte que aquestes continuïtats troben també suport a partir dels escrits de Ghiberti i, sobretot, de Vasari. Com per a altres casos i en paraules de Monciatti: "La rilevanza storico-critica del giudizio vasariano restò cruciale come fatto storiografico» (p. 272). Així, s'estableixen les conseqüències d'aquestes aportacions en les orientacions $d^{\prime}$ estudis subsegüents, una temàtica que ens porta a aquest capítol final del llibre en què es fa balanç més enllà de l'estat de la qüestió i se sospesen pros i contres de cada contribució a l'etapa analitzada i, fins i tot, al pintor estudiat més globalment.

Des del context que descriu la recerca sobre l'art medieval a Catalunya, com a mínim en el darrer quart de segle, no crec que es vacillli per norma sobre la categorització de Giotto com a pintor del Gòtic, en un sentit global, perquè s'entén perfectament que l'art gòtic no és simplement I'art bastit al nord francès, anglès, flamenc 0 germànic a partir del segle XII. Ja sabem que aquesta perspectiva, que dona una pista més ampla al moviment gòtic en la seva ramificació europea, crea més problemes en el context italià. La qüestió mereix ser debatuda amb una ferma declaració que passa per recordar aportacions d'autors no nascuts a Itàlia, així com també el territori trepitjat per Cesare Gnudi, historiador ben conegut en el context català i que Monciatti reivindica —sense eludir altres aportacions, com ara la d'Angiola Maria Romanini- a partir de tesis que va defensar i que apropaven el pintor a I'art septentrional. És prou significatiu el títol de l'assaig de
Gnudi: Sugli inizi di Giotto e i suoi rapporti col mondo gotico. Si

voleu revisar altres connexions historiogràfiques amb el Giotto que ens porta de la capella Peruzzi a la capella Bardi, les trobareu ben detallades en aquest capítol vi i darrer del llibre.

Saber com es va pintar i sobre quines mans recau la responsabilitat última de les pintures conservades, com evolucionen els tallers al llarg del temps i com processen el dibuix, i el color, en cada cas i cada nova circumstància, ens posa davant d'un trencaclosques ben sacsejat que no podrem recompondre sense els coneixements escaients i una bona dosi de sentit comú, que demana seny en I'avaluació històrica i artística. No manquen a l'autor ni els primers ni el segon i, per tant, declino en les pàgines del Ilibre el seguiment d'un discurs que, ja ho he apuntat, és complex i ens apropa a unes obres esplèndides, que van arribar a aconseguir ressò a Catalunya i molts altres indrets $d^{\prime}$ Europa tant a la seva època com en fases posteriors.

El text del llibre es desplega en 309 pàgines, a les quals s'afegiran encara 200 figures, la bibliografia i els índexs, fins a arribar a configurar un volum gruixut de 506 pàgines. Una lectura molt recomanable que arriba per eixamplar, millorar i matisar la nostra visió sobre I'art de Giotto di Bondone. No faria falta aclarir que, per més gòtic que el considerem, fou el creador d'un art nou i essencial per als seus temps i per als que seguirien. Giotto fou un artista tan destacat en la pintura com ho va ser Dante 
Alighieri en el camp literari, per esmentar només un altre autor sempre fonamental per entendre les millors realitats de la cultura més genuïna i excelsa de l'època gòtica.

\section{Rosa Alcoy}

Universitat de Barcelona rosaalcoy@ub.edu

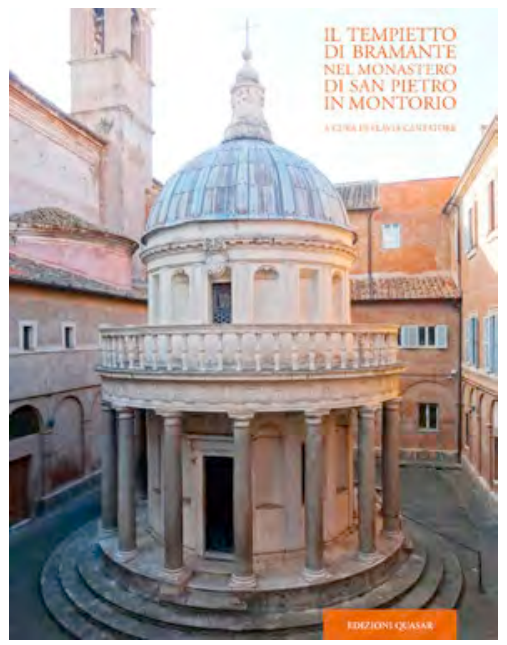

Flavia Cantatore (coord.)

Il Tempietto di Bramante nel monastero di San Pietro in Montorio

\section{Quasar, Roma, 2017}

El tempietto que Bramante diseñó como monumento conmemorativo del lugar donde, según la tradición, san Pedro fue crucificado, fue uno de los edificios renacentistas más loados por sus propios contemporáneos y uno de los más imitados y reproducidos por las generaciones posteriores, todo ello gracias a la aproximación al modelo de la arquitectura antigua que el artista urbinés había conseguido en esta obra. Desde que Sebastiano Serlio incluyó en su tratado la ilustración del edificio - valorada por Arnaldo Bruschi en Bramante architetto, 1969, y también por Christoph Luitpold Frommel en «La città come opera d'arte: Bramante e Raffaello (1500-1520)», en Bruschi (ed.), Storia dell'architettura italiana. Il primo Cinquecento, Electa, 2002-, interpretándolo como perfecta proyección de los valores de la construcción según los cánones del pensamiento clásico, el Tempietto se convirtió en uno de los símbolos por excelencia de la arquitectura del Renacimiento italiano. Fue el boloñés el primero que, en el libro III (1540) de su tratado I sette libbri dell'architettura (1537-

1551), utilizó el término tempietto —que Serlio empleaba para aludir a todos los templos antiguos de dimensiones reducidas - para referirse a la construcción. Serlio había sido discípulo de Baldassarre Peruzzi, y era cercano al círculo de Bramante y de Rafael. Por esta razón, tenía un buen conocimiento de los proyectos producidos por este grupo de arquitectos.

Estos valores, junto con el protagonismo de Bramante en la evolución de la arquitectura renacentista, explican que el monumento ubicado en el complejo de San Pietro in Montorio de Roma haya atraído durante siglos la atención de muchos y significados especialistas. Dejando a un lado las numerosas publicaciones dedicadas al arquitecto en las cuales esta edificación ha ocupado un papel protagonista, como no podía ser de otra manera (la ya citada de Bruschi de 1969, los Studi Bramanteschi: atti del Congresso Internazionale di Studi Bramanteschi de 1970 publicados por De Luca en 1974, la monografía de Franco Borsi editada por Electa en 1989, o el estudio de Luciano Patetta, Bramante: architetto e pittore (1444-1514) de 2009), en los últimos doce años han visto la 
Aquest article ha estat publicat originalment a Matèria. Revista internacional d'Art (ISSN en línia: 2385-3387)

Este artículo ha sido publicado originalmente en Matèria. Revista internacional d'Art (ISSN en línea: 2385-3387)

This article was originally published in Matèria. Revista internacional d'Art (Online IS S N : 2385-3387)

\section{MATÈRIA}

Revista internacional d'Art

Els autors conserven els drets d'autoria i atorguen a la revista el dret de primera publicació de l'obra.

Els textos es difondran amb la llicència de Reconeixement-NoComercialSenseObraDerivada de Creative Commons, la qual permet compartir I'obra amb tercers, sempre que en reconeguin I'autoria, la publicació inicial en aquesta revista i les condicions de la llicència: https://creativecommons. org/licenses/by-nc-nd/4.0/deed.ca

Los autores conservan los derechos de autoría y otorgan a la revista el derecho de primera publicación de la obra.

Los textos se difundirán con la licencia de Atribución-NoComercial-SinDerivadas de Creative Commons que permite compartir la obra con terceros, siempre que éstos reconozcan su autoría, su publicación inicial en esta revista y las condiciones de la licencia: https://creativecommons.org/licenses/ by-nc-nd/4.0/deed.es

The authors retain copyright and grant the journal the right of first publication.

The texts will be published under a Creative Commons Attribution-NonCommercial-NoDerivatives License that allows others to share the work, provided they include an acknowledgement of the work's authorship, its initial publication in this journal and the terms of the license: https://creativecommons.org/licenses/by-nc-nd/4.0/deed.en

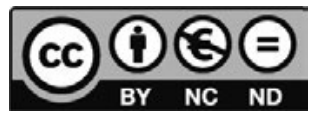

